\title{
Cord bilirubin as a predictor for development of hyperbilirubinemia in term neonates
}

\author{
Anand $\mathbf{K}^{1}$, Rabindran ${ }^{2}$, Gandhimathi $\mathbf{C}^{3}$ \\ ${ }^{1}$ Dr. Anand K, Paediatrician, PIMS, Pondicherry, ${ }^{2}$ Rabindran, Consultant Neonatologist, Billroth Hospital, Chennai, \\ ${ }^{3}$ Dr. Chandara Gandhimathi, Physician, SRMC, Chennai.
}

Address for Correspondence: Dr. Anand. k, E mail: dranandkavin@ gmail.com

\begin{abstract}
Introduction: Hyperbilirubinemia is a common problem among term newborns. Cord bilirubin level has been found to correlate well with day 3 bilirubin level. We studied whether cord bilirubin could predict risk of development of significant hyperbilirubinemia among term neonates. Methodology: Prospective study from October 2009 -July 2010. All newborns between 37 weeks -42 weeks, birth weight $>2500$ gram, Apgar score $>7$ at $1^{\text {st }} \& 5^{\text {th }}$ minute of life were included in the study. Cord blood, day $3 \&$ day 5 bilirubin was collected. Maternal data \& bilirubin values were collected $\&$ analyzed using SPSS software. Results: About 115 babies were studied. There was no significant difference in cord bilirubin \& day 3 bilirubin between babies born to mothers < 30 years \&> 30 years. There was no significant difference in bilirubin values bassed on mode of delivery. About $29.6 \%$ babies developed clinical jaundice \& received phototherapy. Cord bilirubin levels had significant association with need of phototherapy. Cord bilirubin $>/=2.1 \mathrm{mg} / \mathrm{dl}$ predicted need for phototherapy with PPV of $90.3 \%$. Maternal age, sex of baby, birth weight \& gestational age had no significant effect on cord bilirubin levels. Cord bilirubin $>/=2.1 \mathrm{mg} / \mathrm{dl}$ predicted day 3 serum bilirubin $>15 \mathrm{mg} / \mathrm{dl}$ with sensitivity of $88 \%$ \& PPV of $77.49 \%$. The likelihood ratio with cord bilirubin $>2.1 \mathrm{mg} / \mathrm{dl} \&$ day 3 serum bilirubin $>15$ $\mathrm{mg} / \mathrm{dl}$ was 9.316. Conclusion: Cord bilirubin is predictive of need of phototherapy \& correlated well with day 3 bilirubin levels which would facilitate early management of neonatal hyperbilirubinemia.
\end{abstract}

Keywords: Cord bilirubin, Neonatal hyperbilirubinemia, Phototherapy

\section{Introduction}

The commonest problem encountered during neonatal period among term neonates is Hyperbilirubinemia [1], which prolongs hospital stay in a majority of babies. Hyperbilirubinemia is defined as a serum total bilirubin concentration greater than 95th centile for hour of life. Common factors responsible for hyperbilirubinemia among term babies include increased bilirubin load due to relative polycythemia, shortened erythrocyte life span, immature hepatic intake \& conjugation processes along with increased enterohepatic circulation. Uncontrolled hyperbilirubinemia leads to irreversible bilirubin toxicity which is often devastating leading to severe neurologic insult, chronic bilirubin encephalopathy, developmental \& motor delays, sensorineural deafness \& mild mental retardation. Recent practice of early discharge of term newborns

Manuscript received: $6^{\text {th }}$ April 2016 Reviewed: $17^{\text {th }}$ April 2016

Author Corrected; $25^{\text {th }}$ April 2016

Author Corrected; $25^{\text {th }}$ April 2016 places them at high risk for developing bilirubin encephalopathy $[2,3,4]$. Of late, Cord bilirubinlevel is being increasingly studied to define a subgroup of newborns that are at higher risk for developing significant hyperbilirubinemia. Hence this study was done to assess cord bilirubin as a predictor of neonatal hyperbilirubinemia.

Objective: To determine whether cord bilirubin level could predict risk of development of significant hyperbilirubinemia among term neonates.

Study design: Prospective study.

Study area: Neonatal unit of Pondicherry institute of medical sciences (PIMS).

Study period: October 2009- July 2010. 
Study population: Healthy term newborn babies who were born at the maternity unit of PIMS.

Inclusion criteria: All newborn babies with gestational age between 37 weeks \& 42 weeks, birth weight $>2500$ gram, Apgar score of at least 7 at the $1^{\text {st }} \& 5^{\text {th }}$ minute of life were included in the study.

Exclusion criteria: Babies who were of preterm or post term gestation, birth weight $<2500$ gram, Apgar score less than 7 at 5 minutes, Babies with major congenital malformations were excluded from the study.

\section{Methodology}

Parental consent was obtained. Under aseptic conditions umbilical cord blood of the newborn was collected at the time of delivery \& serum bilirubin level was estimated by Jendrassik method in the biochemistry department on all days. All newborns were examined for clinical jaundice by the investigator $\&$ a paediatric consultant. If found icteric treatment was started according to protocol. On day 3 \& day 5, serum bilirubin level was estimated.

Interventions: Phototherapy to icteric babies as per standard unit protocol.

Data Analysis: Data collected were enrolled in excel sheets \& was analyzed using SPSS 17 version (Statistical Package for Social Science). A p-value of $<0.05$ was considered significant.

\section{Results}

About 115 babies were enrolled during the study period. 61 babies (53\%) were male \& 54 babies (47\%) were female.

Table 1: Comparison of cord bilirubin with maternal age, weight \& sex of the baby.

\begin{tabular}{|c|c|c|c|c|c|c|}
\hline & & \multicolumn{5}{|c|}{ Cord Bilirubin } \\
\hline & & & $0.5-1$ & $1.1-2$ & $2.1-3$ & $3.1-4$ \\
\hline \multirow{4}{*}{ 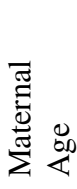 } & $<30$ YEARS & Number & 6 & 62 & 22 & 4 \\
\hline & & $\%$ & 5.2 & 53.9 & 19.1 & 3.5 \\
\hline & $>30$ YEARS & Number & 1 & 15 & 5 & 0 \\
\hline & & $\%$ & 0.9 & 13 & 4.3 & 0 \\
\hline \multirow{6}{*}{$\begin{array}{l}\frac{7}{500} \\
\frac{.00}{0} \\
\frac{10}{2}\end{array}$} & AGA & Number & 6 & 62 & 4 & 95 \\
\hline & & $\%$ & 6.2 & 53.9 & 3.5 & 82.6 \\
\hline & SGA & Number & 0 & 11 & 3 & 0 \\
\hline & & $\%$ & 0 & 9.6 & 2.6 & 0 \\
\hline & LGA & Number & 1 & 4 & 1 & 6 \\
\hline & & $\%$ & 0.9 & 3.5 & 0.9 & 5.2 \\
\hline \multirow{4}{*}{ ڤ્ } & MALE & Number & 1 & 49 & 11 & 0 \\
\hline & & $\%$ & 0.9 & 42.6 & 9.6 & 0 \\
\hline & FEMALE & Number & 6 & 28 & 16 & 4 \\
\hline & & $\%$ & 5.2 & 24.3 & 13.9 & 3.5 \\
\hline
\end{tabular}

About 94 babies (81.7\%) were born to mothers of age between 20-30 yrs. Analysing the bilirubin values based on maternal age, there was no statistically significant difference in the cord bilirubin level \& day 5 bilirubin in babies born to mothers < 30 years of age when compared to mothers > 30 years of age. About $113(98.3 \%)$ of the 115 mothers in the study group had no antenatal medical complication; 1 mother had gestational diabetes \& 1 mother had hypertension. About 65 mothers $(56.5 \%)$ delivered by spontaneous vaginal delivery \& 49 mothers $(42.6 \%)$ delivered by lower segment caesarian section.

Analysing the bilirubin values based on mode of delivery, there was no statistically significant difference in the bilirubin values in babies born by vaginal delivery as compared to babies born by section. About 95 babies (82.6\%) were appropriate for gestational age. About 77 babies (67\%) had cord blood bilirubin in the range of $1.1-2 \mathrm{mg} / \mathrm{dl} \mathrm{whereas} 30$ babies $(27 \%)$ had cord blood bilirubin $>2.1 \mathrm{mg} / \mathrm{dl}$. About 73 babies $(63.5 \%)$ had day 3 serum bilirubin in the range of $10.1-15 \mathrm{mg} / \mathrm{dl}$ whereas 27 babies $(23.5 \%)$ had day 3 serum bilirubin $>15 \mathrm{mg} / \mathrm{dl}$. 
Table 2: Cord bilirubin \& need of phototherapy.

\begin{tabular}{|c|c|c|c|c|}
\hline & \multicolumn{4}{|c|}{ Phototherapy } \\
\hline & & & YES & NO \\
\hline \multirow{8}{*}{ Cord Bilirubin } & $0.5-1$ & Number & 1 & 6 \\
\hline & & $\%$ & 0.9 & 5.2 \\
\hline & 1.1-2 & Number & 9 & 68 \\
\hline & & $\%$ & 7.8 & 59.1 \\
\hline & 2.1-3 & Number & 24 & 9 \\
\hline & & $\%$ & 20.9 & 2.6 \\
\hline & $>3.1$ & Number & 4 & 0 \\
\hline & & $\%$ & 3.5 & 0 \\
\hline
\end{tabular}

About 38 babies $(29.6 \%)$ developed clinical jaundice \& received phototherapy. Cord bilirubin levels had statistically significant association with the need of phototherapy. Cord bilirubin $>/=$ to $2.1 \mathrm{mg} / \mathrm{dl}$ predicted the need for phototherapy with positive predictive value of $90.3 \%$. Maternal age, sex of the baby, birth weight \& gestational age had no statistically significant effect on cord bilirubin levels.

Table 3: Correlation between cord bilirubin \& day 3 serum bilirubin

\begin{tabular}{|c|c|c|c|c|c|c|}
\hline & \multicolumn{6}{|c|}{ Day 3 Bilirubin } \\
\hline & & & 5.1-10 & 10.1-15 & 15.1-20 & $>\mathbf{2 0}$ \\
\hline \multirow{8}{*}{ Cord Bilirubin } & $0.5-1$ & Number & 4 & 3 & 0 & 0 \\
\hline & & $\%$ & 3.5 & 2.6 & 0 & 0 \\
\hline & 1.1-2 & Number & 10 & 64 & 2 & 1 \\
\hline & & $\%$ & 8.7 & 55.7 & 1.7 & 0.9 \\
\hline & 2.1-3 & Number & 1 & 6 & 20 & 0 \\
\hline & & $\%$ & 0.9 & 5.2 & 17.4 & 0 \\
\hline & $>3.1$ & Number & 0 & 0 & 4 & 0 \\
\hline & & $\%$ & 0 & 0 & 3.5 & 0 \\
\hline
\end{tabular}

Table 4: Cord bilirubin versus day 3 serum bilirubin- predictive value

\begin{tabular}{|c|c|c|c|c|c|c|}
\hline \multirow{16}{*}{ 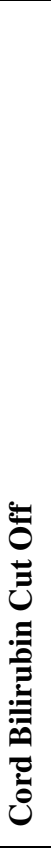 } & & \multicolumn{2}{|c|}{ Total serum bilirubin day 3} & \multirow[t]{2}{*}{ Sensitivity } & \multirow[t]{2}{*}{ Specificity } & \multirow[t]{2}{*}{ PPV } \\
\hline & & $>15$ & $<15$ & & & \\
\hline & $>1.1$ & 24 & 81 & \multirow{2}{*}{$100 \%$} & \multirow{2}{*}{$7.80 \%$} & \multirow{2}{*}{$22.80 \%$} \\
\hline & $<1.1$ & $\mathbf{0}$ & 7 & & & \\
\hline & $>2.1$ & 24 & 7 & \multirow{2}{*}{$88 \%$} & \multirow{2}{*}{$91 \%$} & \multirow{2}{*}{$77.49 \%$} \\
\hline & $<2.1$ & 3 & 81 & & & \\
\hline & & $>13$ & $<13$ & & & \\
\hline & $>1.1$ & 57 & 54 & \multirow{2}{*}{$100 \%$} & \multirow{2}{*}{$100 \%$} & \multirow{2}{*}{$51.30 \%$} \\
\hline & $<1.1$ & $\mathbf{0}$ & 4 & & & \\
\hline & $<2.1$ & 38 & 10 & \multirow{2}{*}{$66.60 \%$} & \multirow{2}{*}{$71.60 \%$} & \multirow{2}{*}{$79.10 \%$} \\
\hline & $<2.1$ & 19 & 48 & & & \\
\hline & & $>10$ & $<\mathbf{1 0}$ & & & \\
\hline & $>1.1$ & 67 & 10 & \multirow{2}{*}{$95.70 \%$} & \multirow{2}{*}{$57 \%$} & \multirow{2}{*}{$87 \%$} \\
\hline & $<1.1$ & 3 & 4 & & & \\
\hline & $<2.1$ & 30 & 1 & \multirow{2}{*}{$30 \%$} & \multirow{2}{*}{$16 \%$} & \multirow{2}{*}{$96.70 \%$} \\
\hline & $<2.1$ & 70 & 14 & & & \\
\hline
\end{tabular}


Table-5: Cord bilirubin versus day 3 bilirubin cut off likely hood ratio.

\begin{tabular}{|c|c|c|c|c|c|c|c|c|c|c|c|}
\hline \multicolumn{12}{|c|}{ Day 3 Bilirubin } \\
\hline & & & $>15$ & $<15$ & LR & $>13$ & $<13$ & LR & $>10$ & $<10$ & LR \\
\hline \multirow{8}{*}{ ن } & $0.5-1$ & Number & 0 & 7 & \multirow{2}{*}{0} & 0 & 4 & \multirow{2}{*}{0} & 3 & 4 & \multirow{2}{*}{0.11} \\
\hline & & $\%$ & 0 & 7.95 & & 0 & 7 & & 3 & 26.6 & \\
\hline & $1.1-2$ & Number & 3 & 74 & \multirow{2}{*}{0.13} & 20 & 43 & \multirow{2}{*}{0.45} & 67 & 10 & \multirow{2}{*}{1} \\
\hline & & $\%$ & 11.1 & 84.09 & & 34 & 75.4 & & 67 & 66.6 & \\
\hline & $2.1-3$ & Number & 20 & 7 & \multirow{2}{*}{9.316} & 35 & 10 & \multirow{2}{*}{0.44} & 26 & 1 & \multirow{2}{*}{3.9} \\
\hline & & $\%$ & 74.07 & 7.95 & & 60.3 & 17.5 & & 26 & 6.6 & \\
\hline & $>3.1$ & Number & 4 & 0 & \multirow{2}{*}{14.81} & 3 & 0 & \multirow{2}{*}{0} & 4 & 4 & \multirow{2}{*}{0} \\
\hline & & $\%$ & 14.81 & 0 & & 5.1 & 0 & & 4 & 0 & \\
\hline
\end{tabular}

In this study cord bilirubin $>/=$ to $2.1 \mathrm{mg} / \mathrm{dl}$ predicted day 3 serum bilirubin level $>15 \mathrm{mg} / \mathrm{dl}$ with a sensitivity of $88 \%$ $\&$ positive predictive value of $77.49 \%$. The likelihood ratio with cord bilirubin cut off $>2.1 \mathrm{mg} / \mathrm{dl} \&$ day 3 serum bilirubin $>15 \mathrm{mg} / \mathrm{dl}$ was 9.316 . Cord bilirubin $>/=1.1 \mathrm{mg} / \mathrm{dl}$ predicted day 3 serum bilirubin level $>15 \mathrm{mg} / \mathrm{dl}$ with a sensitivity of $100 \% \&$ positive predictive value of $22.8 \%$. The likelihood ratio with cord blood bilirubin cut off 1.1-2.0 $\mathrm{mg} / \mathrm{dl} \&$ day 3 serum bilirubin $>15 \mathrm{mg} / \mathrm{dl}$ was 0.13 . Cord bilirubin $>/=$ to $2.1 \mathrm{mg} / \mathrm{dl}$ predicted day 3 serum bilirubin level $>13 \mathrm{mg} / \mathrm{dl}$ with a sensitivity of $66.66 \% \&$ positive predictive value of $79.1 \%$. The likelihood ratio with cord blood bilirubin cut off $>2.1 \mathrm{mg} / \mathrm{dl} \&$ day 3 serum bilirubin $>13 \mathrm{mg} / \mathrm{dl}$ was 3.44 . Cord bilirubin $>/=1.1 \mathrm{mg} / \mathrm{dl}$ predicted day 3 serum bilirubin level $>15 \mathrm{mg} / \mathrm{dl}$ with a sensitivity of $100 \% \&$ positive predictive value of $51.3 \%$. The likelihood ratio with cord blood bilirubin cut off $1.1-2.0 \mathrm{mg} / \mathrm{dl} \&$ day 3 serum bilirubin $>15 \mathrm{mg} / \mathrm{dl}$ was 0.45 . Cord bilirubin $>/=$ to 2.1 $\mathrm{mg} / \mathrm{dl}$ predicted day 3 serum bilirubin level $>10 \mathrm{mg} / \mathrm{dl}$ with a sensitivity of $30 \%$ \& positive predictive value of $96.7 \%$. The likelihood ratio with cord blood bilirubin cut off $>2.1 \mathrm{mg} / \mathrm{dl} \&$ day 3 serum bilirubin $>10 \mathrm{mg} / \mathrm{dl}$ was 3.9. Cord bilirubin $>/=1.1 \mathrm{mg} / \mathrm{dl}$ predicted day 3 serum bilirubin level $>15 \mathrm{mg} / \mathrm{dl}$ with a sensitivity of $95.7 \% \&$ positive predictive value of $87 \%$. The likelihood ratio with cord blood bilirubin cut off $1.1-2.0 \mathrm{mg} / \mathrm{dl} \&$ day 3 serum bilirubin $>$ $10 \mathrm{mg} / \mathrm{dl}$ was 1.0 .

\section{Discussion}

Reticulocyte count, positive direct antiglobulin test \& presence of a sibling with neonatal jaundice have been considered as good predictors for the development of significant hyperbilirubinemia. Studies have shown that critical bilirubin levels of $4 \mathrm{mg} / \mathrm{dl} \& 6 \mathrm{mg} / \mathrm{dl}$ at the $6^{\text {th }}$ hour of life predicted occurrence of significant hyperbilirubinemia \& development of severe haemolytic disease of the newborn, respectively $[3,5]$. There is an association between bilirubin levels in cord blood \& later neonatal bilirubin concentration $[6,7,8]$. Mean bilirubin levels in cord blood range from 1.4 to $1.9 \mathrm{mg} / \mathrm{dl}[9,10]$ \& elevated cord bilirubin levels was associated with an increased risk of hyperbilirubinemia [7,9,10]. Risenberg et al [11] observed that babies with cord bilirubin more than $4 \mathrm{mg} / 100 \mathrm{ml}$ were at risk of developing severe hyperbilirubinemia. Rosenfeld et al., [12] concluded that babies with cord bilirubin level < $2 \mathrm{mg} / \mathrm{dl}$ had $4 \%$ chance of developing significant jaundice as compared to a $25 \%$ chance of developing significant jaundice in newborns with level $>2 \mathrm{mg} / \mathrm{dl}$. Knudson A [6] noted that need of phototherapy was statistically significant among newborns with cord bilirubin levels $>2.3 \mathrm{mg} / \mathrm{dl}$ as compared to babies with bilirubin < $2.3 \mathrm{mg} / \mathrm{dl}$. Mathias Katfer et al.,[13] observed that newborns with cord bilirubin > 30 micromol/ litre predicted need of phototherapy with a sensitivity of $90 \% \&$ a negative predictive value of $99.1 \%$. Serum cord total bilirubin levels can define a subgroup of infants who are at a higher risk for developing significant hyperbilirubinemia\& requirement of phototherapy. Yamauchi Y et al., [7] observed that babies delivered by caesarean section had significant lower values of cord bilirubin as compared to babies delivered vaginally which was explained due to decreased placental transfusion during caesarean section. In our study there was no significant difference based on the mode of delivery. Srivastsav N et al., [14] in his study comparing newborns born to mothers with age $<30$ years and mothers $>30$ years found that babies born to younger mothers had higher bilirubin on day 3 $\&$ day 5 . However no statistically significant difference was observed on cord bilirubin. In our study there was no statistically significant difference in the cord bilirubin level \& day 5 bilirubin in babies born to mothers $<30$ years of age as compared to mothers $>30$ years of age. 


\section{Conclusion}

Umbilical cord bilirubin is useful in predicting the postnatal bilirubin value on day $3 \&$ need for phototherapy in normal term newborns. Cord bilirubin cut off of $>/=2.1 \mathrm{mg} / \mathrm{dl}$ among term neonates is a good predictor of total serum bilirubin $>15 \mathrm{mg} / \mathrm{dl}$ with good sensitivity \& positive predictive value which would facilitate targeted intervention of babies at high risk of hyperbilirubinaemia in a safe \& cost effective manner.

Recommendations: Umbilical cord blood bilirubin of term newborn babies would facilitate early intervention in the management of neonatalhyperbilirubinemia thereby reducing hospital stay in a resource limited country like ours.

\section{Abbreviations: \\ CB- cord bilirubin \\ TSB- total serum bilirubin \\ PPV-positive predictive value \\ LR- likelihood ratio \\ PT- phototherapy \\ Funding: Nil, Conflict of interest: Nil Permission from IRB: Yes}

\section{Reference}

1. Avery text book of neonatology 18th edition, 2009.

2. Alpay F, Sarici SU, Tosuncuk HD, Serdar MA, Inanç $\mathrm{N}$, Gökçay E. The value of first-day bilirubin measurement in predicting the development of significant hyperbilirubinemia in healthy term newborns.Pediatrics. 2000 Aug;106(2):E16.

3. Cohen RS, Wong RJ, Stevenson DK. Understanding neonatal jaundice: a perspective on causation. Pediatr Neonatol. 2010 Jun;51(3):143-8. doi: 10.1016/S18759572(10)60027-7.

4. Soskolne El, Schumacher R, Fyock C, et al. The effect of early discharge and other factors on readmission rates of newborns. Arch Pediatr Adolesc Med 1996:150:373-379
5. Sarici SU, Yurdakök M, Serdar MA, Oran O, Erdem G, Tekinalp G, YiğitS. An early (sixth hour) serum bilirubin measurement is useful in predicting the development of significant hyperbilirubinemia and severe $\mathrm{ABO}$ hemolytic in a selective high risk population of newborns with ABO incompatibility. Pediatrics. 2002 Apr;109(4):e53.

6. Knudsen A, Lebech M. Maternal bilirubin, cord bilirubin and placental function at delivery in the development of jaundice in mature newborns. Acta Obstet Gynecol Scand 1989 (Jan); 68:719-724.DOI: $10.3109 / 00016348909006145$

7. Yamuchi et al. Difference in TCB readings between full term newborn infants regionally of caeserean section. Actascand. 1998 Nov; 78(6): 824-8.

8. Ip S, Chung M, Kulig J, O'Brien R, Sege R, Glicken S, Maisels MJ, Lau J. An evidence-based review of important issues concerning neonatal hyper bilirubinemia. Pediatrics 2004; July 114(1)263-264.

9. Maisels MJ, Kring EA. Length of stay, jaundice and hospital readmission.Pediatrics. 1998 Jun;101(6):995-8.

10. Frishberg $\mathrm{Y}$, Zelikovic I, Merlob $\mathrm{P}$, et al. Hyperbilirubinemia and influencing factors in term infants. Isr J Med Sci 1989;25:28-31.

11. Risemberg HM, Mazzi E, MacDonald MG, Peralta M, Heldrich F.Correlation and Cord bilirubin levels with Hyperbilirubinemia in ABO incompatibility. Arch Dis Child. 1977 Mar;52(3):219-22.

12. Rosenfeld J. Umblical cord as a Predictor of subsequent of hyperbilirubinemia. J Fam Pract. 1986 Dec;23(6):556-8.

13. Mathias knofer, Ferdinand Pulsar, Corrina Predictive value of cord bilirubin for post natal hyperbilirubinemia. Acta paediatrica,vol 94,2005,581587.

14. Srivastava $\mathrm{N}$ et al. A study of serum bilirubin in neonates in relation to maternal age. Indian J Med Sai. 1999 Apr; 53(4); 154-6.

\section{How to cite this article?}

Anand K, Rabindran, Gandhimathi C. Cord bilirubin as a predictor for development of hyperbilirubinemia in term neonates. Int J Pediatr Res 2016;3(5):308-312.doi:10.17511/ijpr.2016.i05.07 